SR 191

CRAEL

Special Report 191

\title{
GROUND RESISTIVITY SURVEY IN THE AREA OF THE TENNESSEE - TOMBIGBEE WATERWAY
}

\author{
Pieter Hoekstra and Allan J. Delaney
}

August 1973

PREPARED FOR

U.S. ARMY ENGINEER DISTRICT, MOBILE., ALABAMA

BY 
The findings in this report are not to be construed as an official Department of the Army position unless so designated by other authorized documents. 


\title{
GROUND RESISTIVITY SURVEY IN THE AREA OF THE TENNESSEE - TOMBIGBEE WATERWAY
}

\author{
Pieter Hoekstra and Allan J. Delaney
}

August 1973

PREPARED FOR

U.S. ARMY ENGINEER DISTRICT, MOBILE, ALABAMA

BY 


\section{PREFACE}

This' report was prepared by Dr. Pieter Hoekstra, Research Physicist. and Allan J. Delaney, Physieal Sciences Technician, Physical Sciences Braneh. Research Division, U.S. Army Cold Regions Research and Engineering Laboratory. The work was performed for the Office of the District Engineer.. Mobile, Alabama, District, U.S. Army Corps of Engineers under Contract Order No. 73=049.

Carroll Winter of the Mobile District served as a valuable guide, and imparted much of his geological knowledge of the area to the USA CRREL field party. All data on soil profiles used in this report were provided by the Mobile District.

The help of Paul Sellmann in locating geological information for the area, and his critical review, are appreciated.

The contents of this report are not to be used for advertising, publication, or promotional purposes. Citation of trade names does not constitute an official endorsement or approval of the use of such commercial produets.

Manuscript received 18 June- 1.973 


\section{CONTENTS}

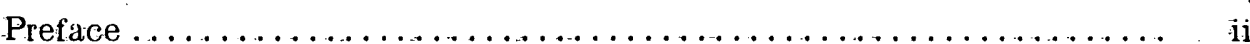

Introduction $\ldots \ldots \ldots \ldots \ldots \ldots \ldots \ldots \ldots \ldots \ldots \ldots \ldots \ldots \ldots \ldots \ldots \ldots \ldots$

Field methods used for measuring the electrical resistivity . . . . . . . . 1

In situ measurements in exposures $\ldots \ldots \ldots \ldots \ldots \ldots \ldots \ldots \ldots \ldots$

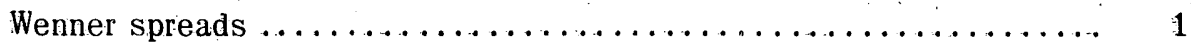

E-phase measurements on the ground $\ldots \ldots \ldots \ldots \ldots \ldots \ldots \ldots \ldots$

Results and discussion $\ldots \ldots \ldots \ldots \ldots \ldots \ldots \ldots \ldots \ldots \ldots \ldots \ldots \ldots \ldots$

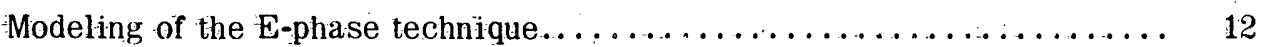

Conclusions and recommendations $\ldots \ldots \ldots \ldots \ldots \ldots \ldots \ldots \ldots \ldots$

Literature cited $\ldots \ldots \ldots \ldots \ldots \ldots \ldots \ldots \ldots \ldots \ldots \ldots \ldots$

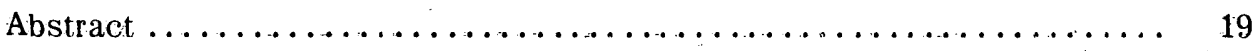

Figure

\section{ILLUSTRATIONS}

1. Tennessee - Tombigbee Waterway................... 3

2. Assumed geologic cross section on which the computations are based 3

3. Electromagnetic field components of a vertically polarized radio sur-

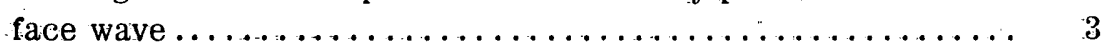

4. The relation between $E_{X} / E_{Z}$ and resistivity for a homogeneous earth

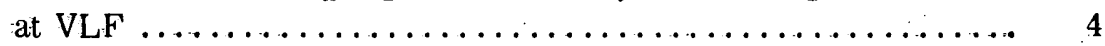

5. Skin depth of electromagnetic plane waves as a function of frequency 4

6 . The apparent resistivity, $\rho_{a}$, obtained in a Wenner spread as a func-

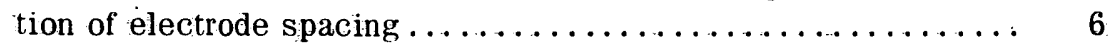

7. The resistivity of soil types measured in exposures $\ldots \ldots \ldots \ldots .68$

8. Comparison - of the ground profiles obtained with the Wenner method and from the borelogs $\ldots \ldots \ldots \ldots \ldots \ldots \ldots \ldots \ldots \ldots . . . \ldots$

9. The computed apparent resistivity for the E-phase method for the layered situations shown on the figure ................ 11

10. The apparent resistivity computed for the E-phase method for the layered situations shown on the figure $\ldots \ldots \ldots \ldots \ldots \ldots \ldots . .13$

11. The apparent resistivity computed for the E-phase method for the layered situation shown on the figure $\ldots \ldots \ldots \ldots \ldots \ldots \ldots$.

Table

I. Classification of soil profiles ..................... 10

II. Results of measurements with the E-phase unit at a frequency of

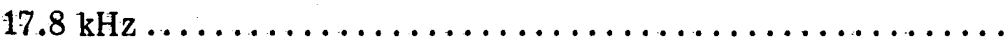

III. Classification of soils based on bore logs compared with classification from VLF measurements and theoretical computations...... 


\title{
GROUND RESISTIVITY SURVEY IN THE AREA OF THE TENNESSEE - TOMBIGBEE WATERWAY
}

by

\author{
Pieter Hoekstra and Allan J. Delaney
}

\section{Introduction}

Because it is difficult to reach most of the area of the proposed Tennessee - Tombigbee Waterway with drilling equipment, the Mobile, Alabama, District of the Corps of Engineers requested that CRREL determine what subsurface information could be obtained by airborne electrical resistivity methods.

Mapping of geological strata by electrical resistivity techniques requires that the strata to be distinguished have substantial differences in resistivity. A preliminary ground survey is, therefore, often required to ascertain typical resistivity values of the strata and the disposition of these layers in a depth profile. Such a ground survey forms the basis for 1) deciding if an airborne survey has merit, and 2) determining the resistivity values of geological strata.

Such a ground resistivity survey was made in the area of the Tennessee - Tombigbee Water. way between 14 and 18 May 1973. A map of the area is shown in Figure 1. The geology of the area surveyed can, in general, be characterized as an alluvial overburden over a Cretaceous substratum called the Eutah formation. The Eutah formation consists, essentially, of a gray to greenish, fine- to medium-grained glauconitic sand, crossbedded with massive and laminated, dark colored bentonitic clay. Only at the northern boundary of Pool E are some sandstone, slate and limestone formations found.

\section{Field methods used for measuring the electrical resistivity}

Three methods were used to characterize the electrical resistivity of the ground.

In situ measurements in exposures. To obtain the resistivity of a certain soil layer, four stainless steel probes were inserted in it, spaced $4 \mathrm{in}$. apart. The resistivity was measured with a Bison Model 2350 resistivity meter which uses a 9-cycle square wave. Normally a shallow pit was dug to obtain the resistivity values of the top soil layers. In some situations measurements were made in existing exposures such as gravel pits and road cuts.

Wenner spreads (Keller and Frischknecht 1966). Depth soundings were made using a Wenner array, in which four electrodes are placed in a line at equal distances apart. A current is passed through the two outer electrodes, and the induced potential is measured between the inner electrodes. A Bison Model 2350 resistivity meter was used.

Increasing the spacing between the electrodes increases the depth to which subsurface information may be obtained. The depth of penetration is about equal to the distance between two electrodes. The maximum electrode spacing used was $30 \mathrm{~m}(90 \mathrm{ft})$. 
For a homogeneous earth material there is a direct, simple relation between the resistivity of the material, the current flow, and the potential difference, i.e.:

$$
\rho=2 \pi \mathrm{a} \frac{V}{I}
$$

where $\rho=$ resistivity of the ground, ohm-meters

$a=$ electrode spacing, meters

$V=$ potential difference between the inner electrodes, volts

$I=$ current flowing between-the outer electrodes, amperes

When the earth is not homogeneous, but has several layers of different resistivity, $\rho_{1} ; \rho_{2}$, $\rho_{3} \ldots$, and with the depth to the lower boundaries of the layers, $d_{1}, d_{2}, d_{3} \ldots$, as shown in Figure 2 , one defines an apparent resistivity $\rho_{\mathrm{a}}$ by

$$
\rho_{\mathrm{a}}=2 \pi \mathrm{a} \frac{V}{I}
$$

The value of the apparent resistivity changes with electrode spacing and is a complex function of $\rho_{1}, \rho_{2}, \rho_{3} \ldots$, and $d_{1}, d_{2}, d_{3} \ldots$ In the field $\rho_{\mathrm{a}}$ is measured, and $\rho_{1}, \rho_{2} \rho_{3} \ldots$ and $d_{1}, d_{2}, d_{3} \ldots$ are obtained by an inverse solution to the field curve by means of a computer program. The computer program can handle up to four layers.

E-phase measurements on the ground (Hoekstra and McNeill 1973). 'The E-phase method uses radio waves transmitted by military and civilian stations. When both the receiver and the transmitter are near the ground, the signals received travel by ground wave. The electromagnetic field components of the ground wave are given in Figure 3. The radio station transmits a vertically polarized radio wave, i.e. a vertical electric field $E_{z}$ and a horizontal magnetic field $H_{y}$ perpendicular to the direction of propagation. The wave also penetrates into the ground with a horizontal magnetic field $H_{y}$ and a horizontal electric field $E_{x}$. The field vectors $H_{y}$ and $E_{z}$ are continuous across the ground surface. Thus, $E_{X}$ can be measured with probes in the ground as well as with an antenna in the air. The horizontal electric field is in a radial direction from the transmitter, and a horizontal antenna must thus be oriented in that direction.

The field vector $E_{x}$ has a different, phase than $E_{z}$ or $H_{y}$, which have the same phase. Thus, $E_{X}$ can be considered to be made up of two components in time relative to $E_{Z}$ : an in-phase and a quadrature phase ( $90^{\circ}$ out of phase) component. One normally measures the ratio of $E_{\mathbf{X}} / E_{z}$ or $E_{x} / H_{y}$, so as to avoid having to make absolute measurements of field strength. Also the ratio $E_{x} / E_{z}$ or $E_{x} / H_{y}$ is a local measurement, related to the impedance of the ground, and independent of the ground traversed by the radio wave between transmitter and receiver. The relation between $E_{\boldsymbol{x}} / E_{\boldsymbol{z}}$ and resistivity for a homogeneous earth at VLF is given in Figure 4. When the earth is layered rather than homogeneous an apparent resistivity can again be computed from well established relations.

The depth to which the radiation penetrates the earth depends on the frequency and the resistivity (Fig. 5). When the frequency is increased the depth of penetration diminishes. The effect of changing the frequency is like changing the spacing between the electrodes in a Wenner array. For example, a VLF survey would be equivalent to traversing with a Wenner array with a fixed probe spacing of 50 to $100 \mathrm{~m}$, while a survey at broadcast band $660 \mathrm{kHz}$ would correspond approximately to a traverse with a fixed probe spacing of about $15 \mathrm{~m}$. 


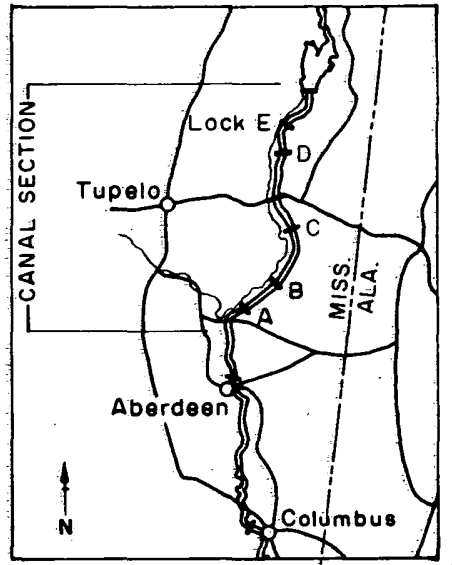

Figure 1. Tennessee - Tombigbee Waterway.

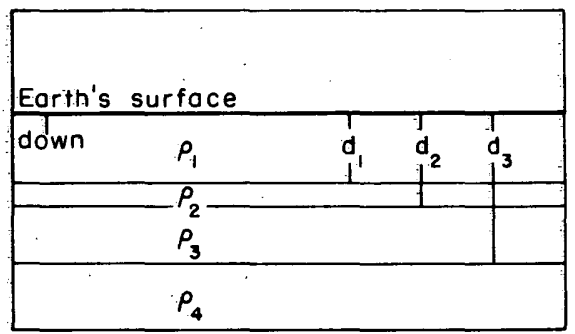

Figure 2. Assumed geologic cross section on which the computations are based. $\rho=$ electrical resistiv $*$ ity; $\mathrm{d}=$ depth.

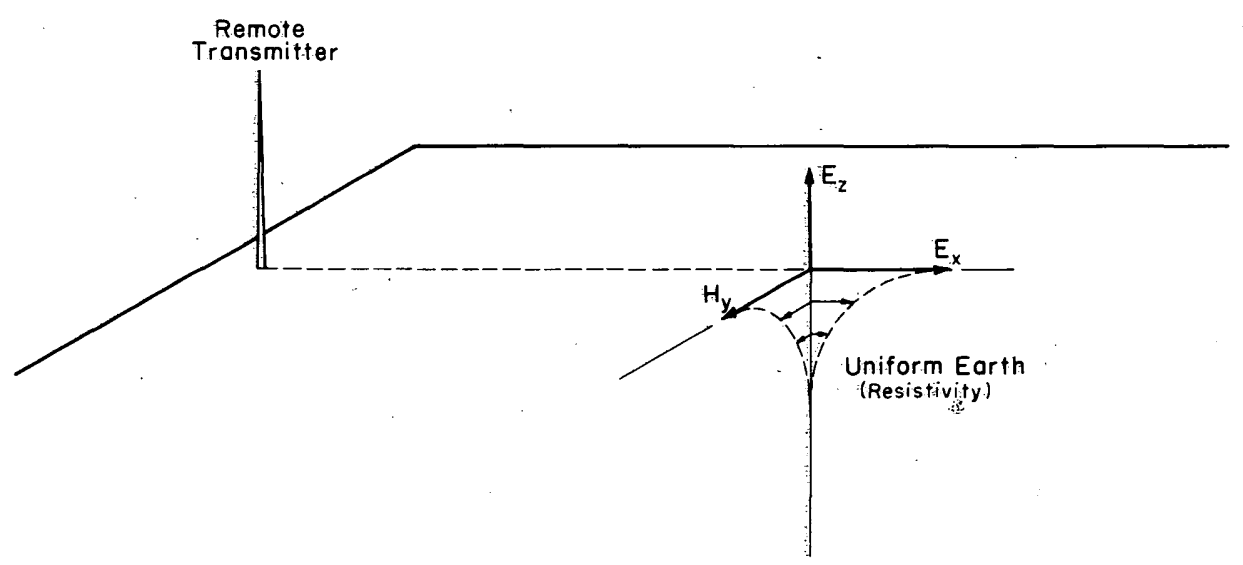

Figure 3. Electromagnetic field components of a vertically polarized radio surface wave. 


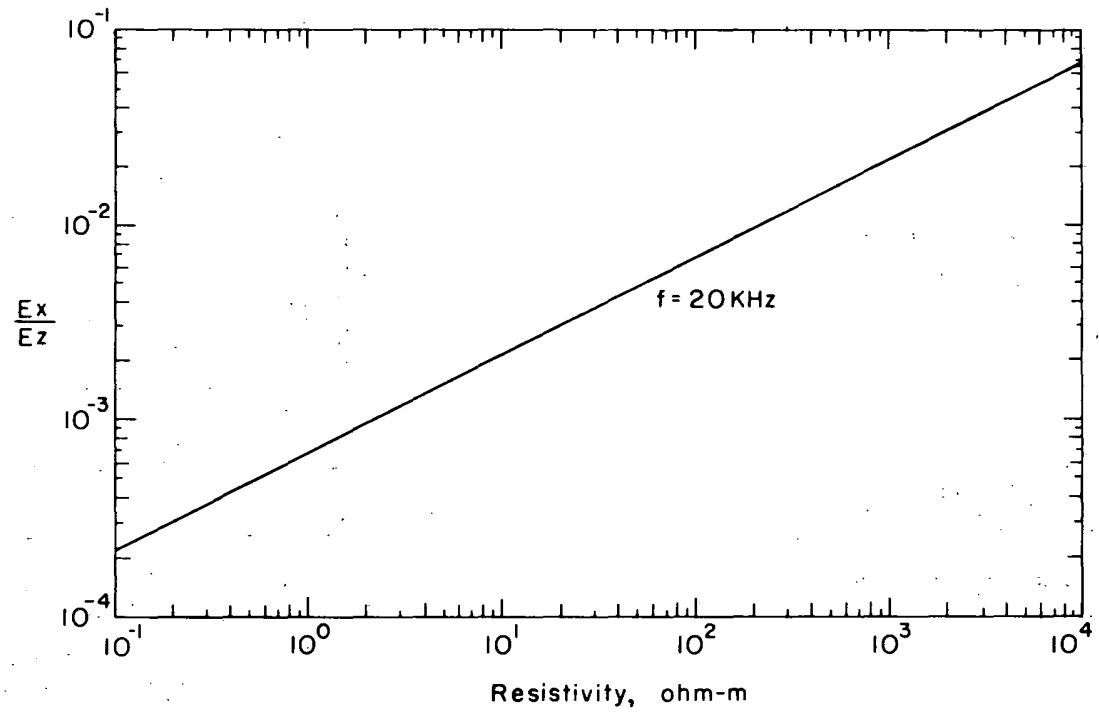

Figure 4. The relation between $\mathrm{E}_{\mathrm{x}} / \mathrm{E}_{z}$ and resistivity for a homogeneous earth at $V L F$.

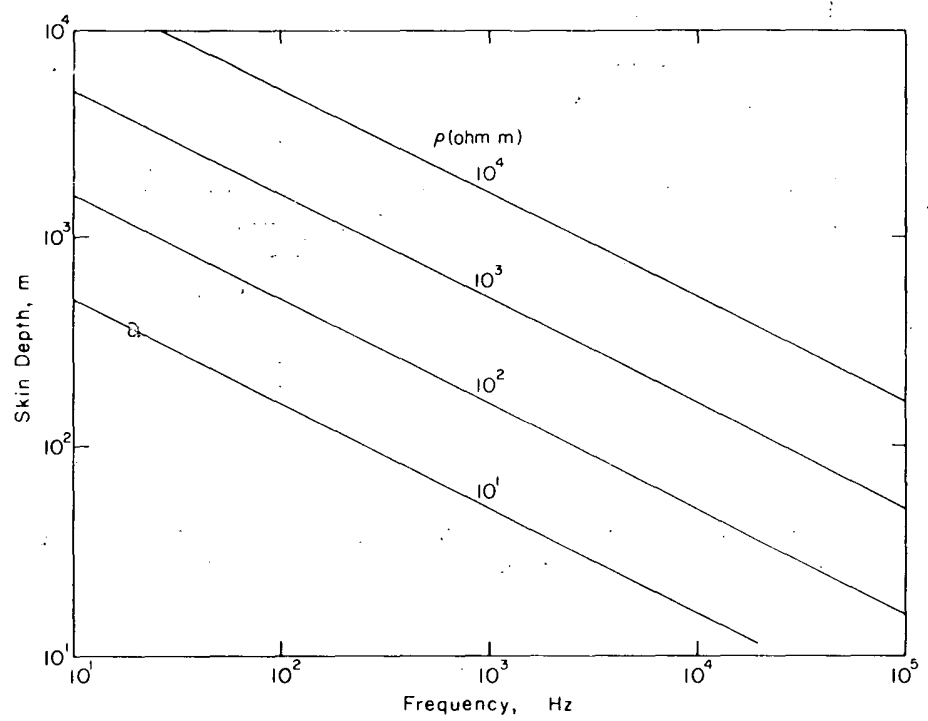

Figure 5. Skin depth of electromagnetic plane waves as a function of frequency. 
A resistivity survey can be made either from an airborne platform or on the ground. On the ground a Geonics $16 \mathrm{R}$ was used, which measures $E_{x}$ through probes in the ground and $H_{y}$ in the air at the surface.

During the ground field survey only the frequencies of $17.8 \mathrm{kHz}$ (NAA, Cutler, Maine) and $24 \mathrm{kHz}$ (NBA, Panama) were used, because some of the equipment needed for higher frequencies is not sufficiently portable for routine field work. An airborne resistivity survey would use selected frequencies between $17.8 \mathrm{kHz}$ and $1 \mathrm{MHz}$.

\section{Results and discussion}

The Wenner resistivity soundings are given in Figure 6 . In all parts of this figure the solid line represents a computer calculation of the layered situation indicated and the points are the experimental field data. A best fit is obtained by trying selected values of $d$ and $\rho$. In most instances a good fit is obtained after two or three tries.

The values of $d_{1}, d_{2}, d_{3} \ldots$ represent the depths from the surface to the lower boundaries of layers $1,2,3 \ldots$ as shown in Figure 2. Likewise $\rho_{1}, \rho_{2}, \rho_{3} \ldots$ represent the resistivities in ohmmeters of layers $1,2,3 \ldots$. The thickness of the bottom layer is assumed infinite for the purpose of these soundings. Thus, for example, in profile A67a the solid line represents the computed apparent resistivity for the case where the first layer has a thickness of $1 \mathrm{~m}$ and a resistivity of $150 \mathrm{ohm}-\mathrm{m}$, the second layer is $7 \mathrm{~m}(8-1)$ thick and has a resistivity of $800 \mathrm{ohm}-\mathrm{m}$. The third layer begins at $8 \mathrm{~m}$ below the surface, extends to a depth well beyond $20 \mathrm{~m}$ and has a resistivity of $50 \mathrm{ohm}-\mathrm{m}$.

In general good agreement between computed values and experimental values was obtained. The main cause for deviation is lateral variation in resistivity. The Wenner electrode conf iguration averages the resistivities over an area three times the electrode spacing. Thus for an electrode separation of $30 \mathrm{~m}$ the apparent resistivity represents an average value over a distance of $90 \mathrm{~m}$. Clearly, over such a distance lateral variations in soil type do occur, particularly in this area.

The results of the measurements on separate soil layers, and in exposures, are summarized in Figure 7, where the resistivity of the soil types encountered is given. The resistivity follows the normal pattern, increasing when the clay content decreases. If one places all fine-grained soils (CH, CL, ML, SC, MH) in one group and all coarse-grained soils (SM, GM, GP, GC) in another, the first group has a range from $50-300 \mathrm{ohm}-\mathrm{m}$, and the latter from 200 to $2500 \mathrm{ohm}-\mathrm{m}$. In the area it was rare to see sharp transitions.

The measurements on the individual soil layers make it possible to assign soil types to the resistivity layering given in Figure 6 and to compare these profiles with actual bore logs. This has been done in Figure 8. In comparing these results it is important to note that a bore log is a very local measurement, while the resistivity averages the result over a substantial distance. If this is kept in mind the agreement is, in most cases, good. In profile B48 the layer sequences are correct, and the layer thicknesses differ somewhat, probably due to local variation. The agreement in profiles E2, E1, E4 and E5 is excellent.

The resistivity method often fails to detect a coarse-grained layer (SM, GM, SP) sandwiched between two clay layers. This is, for example, the case in profile C38, and the lower coarse layers of A75 and D23. However, often such layers may occur in lenses penetrated by the drilling but not continuous over a distance of $90 \mathrm{~m}$. Clearly, the best use of resistivity is in situations where the contrasts are sharp (E2, E1, E5, E4) and when not more than three layers are present. 

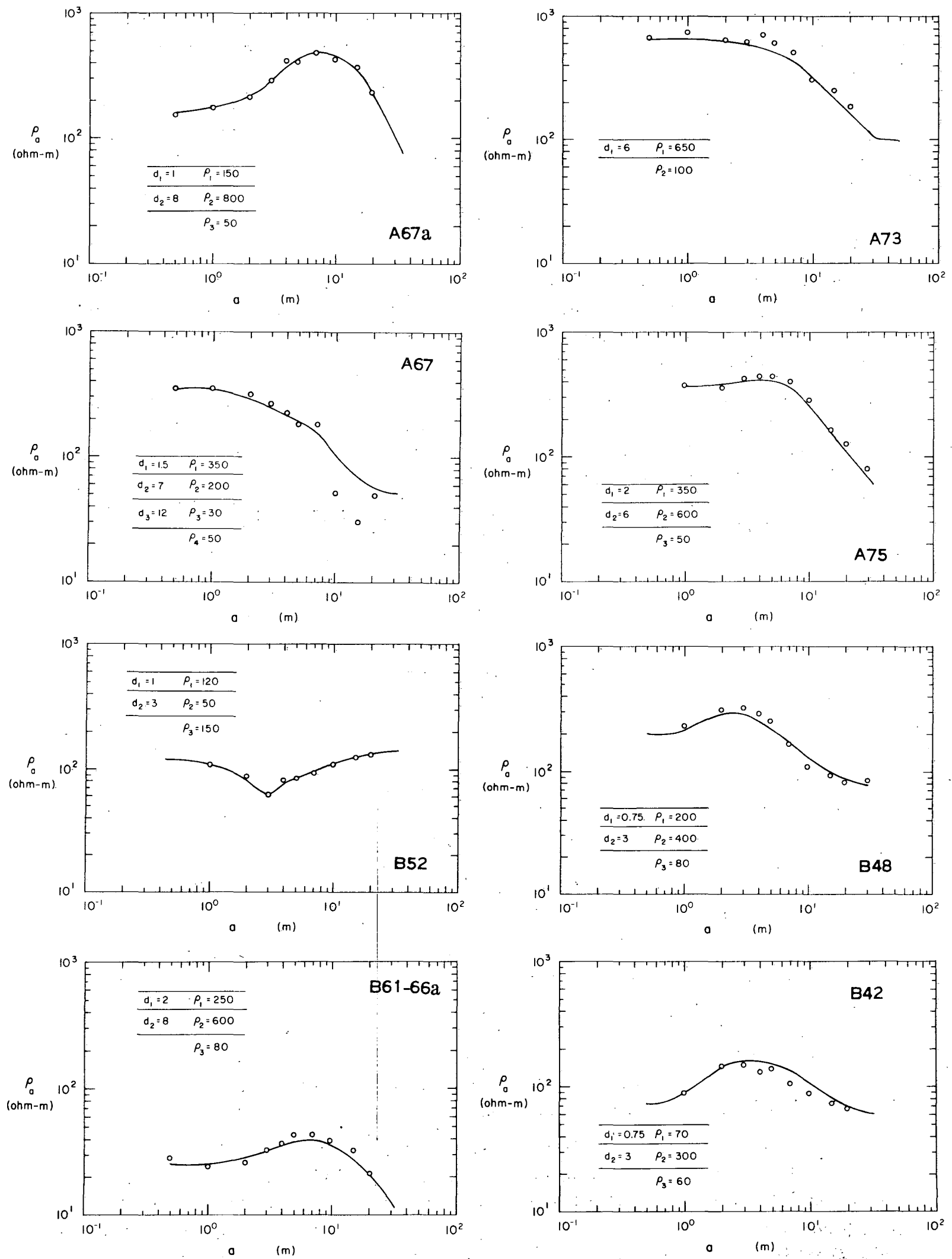

Figure 6. The apparent resistivity, $\rho_{\mathrm{a}}$, obtained in a Wenner spread as a function of electrode spacing. The solid line represents the computed values for the layered situation indicated on the figure. The values of d stated are the depth from the surface to the lower boundary of a layer. 

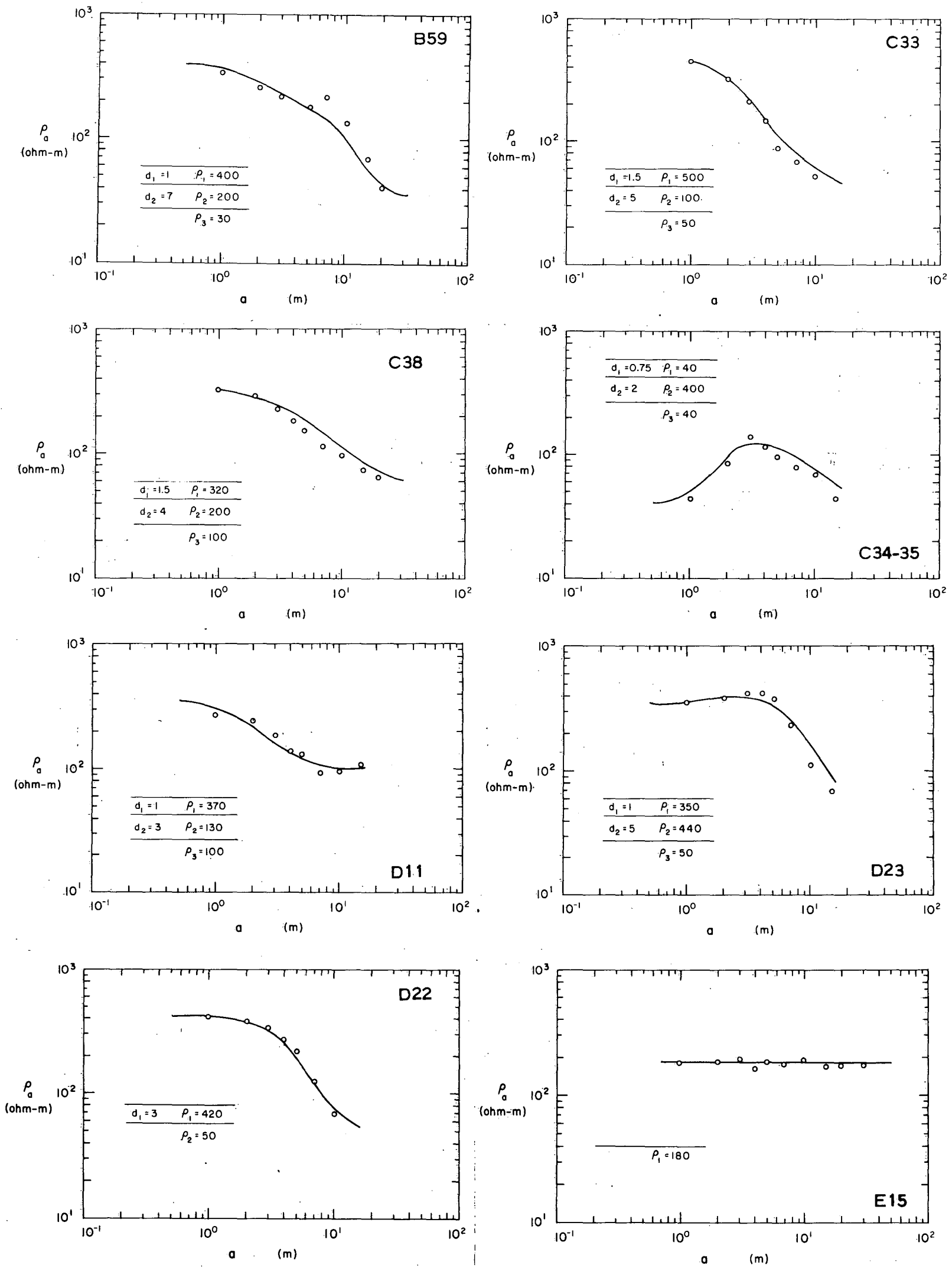

Figure 6 (Cont'd). 

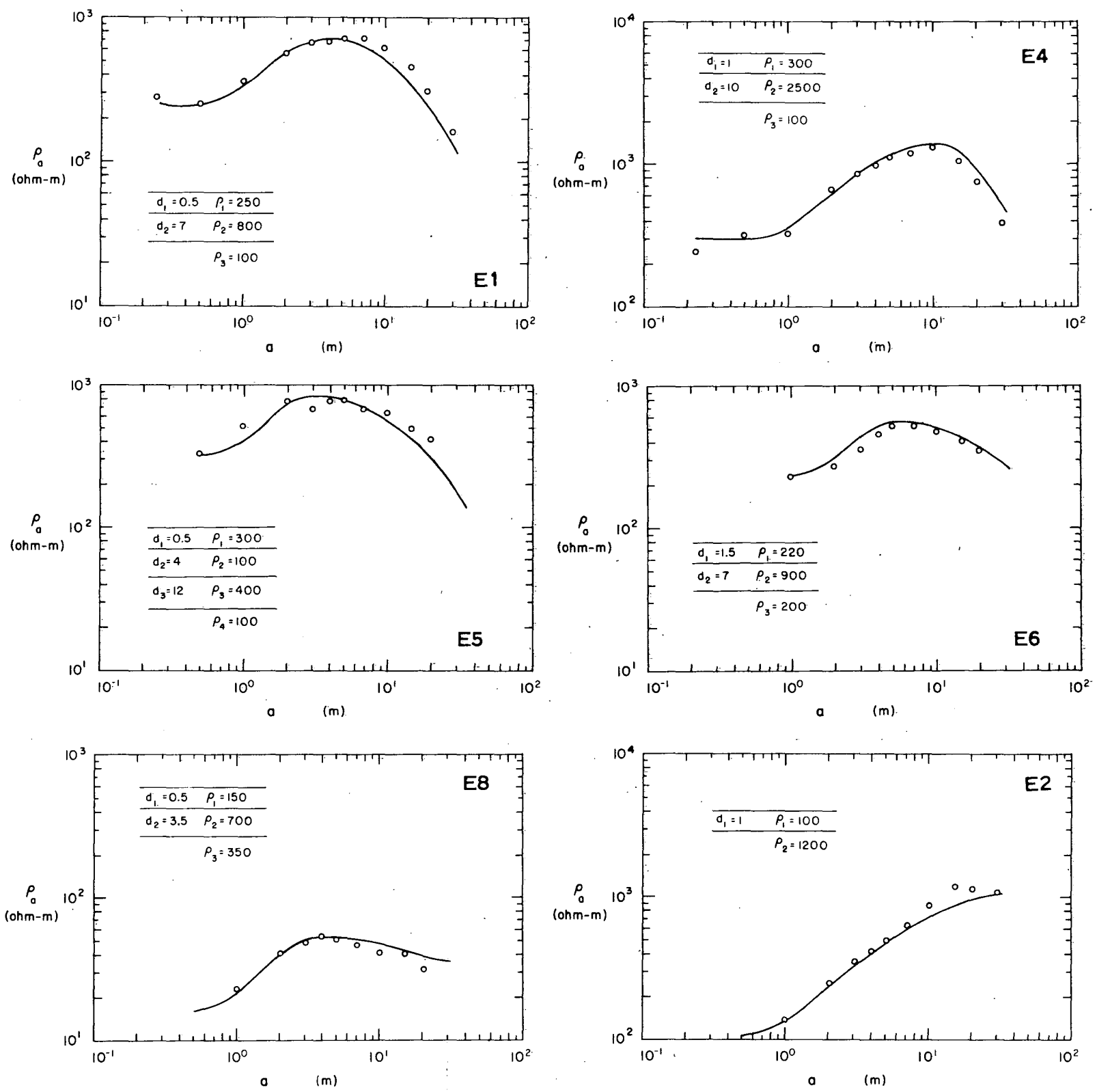

Figure 6 (Cont'd).

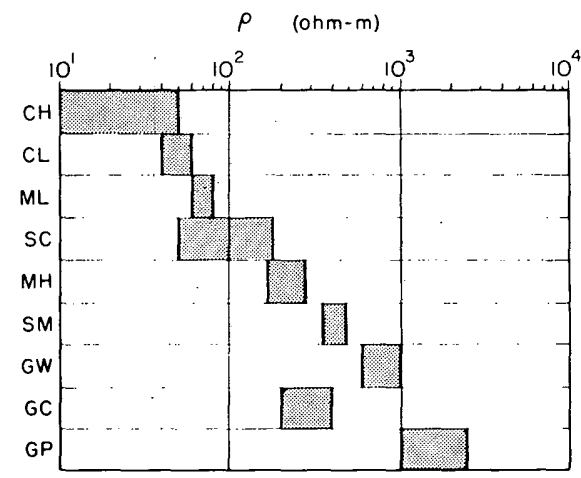

Figure 7. The resistivity of soil types measured in exposures. 

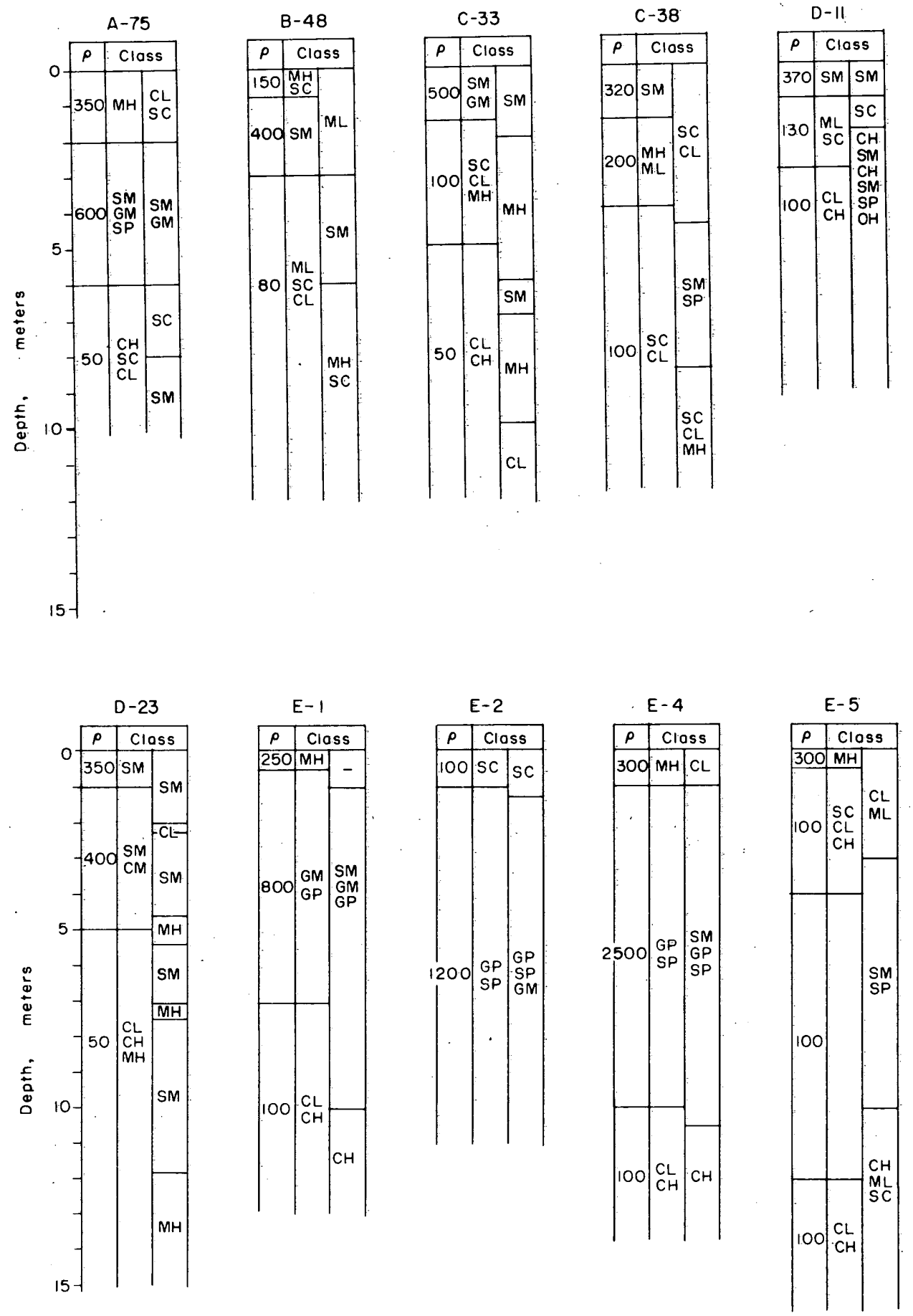

Figure 8. Comparison of the ground profiles obtained with the Wenner method and from the borelogs. Column 1 gives the resistivity of each layer identified, column 2 the assignment to a certain soil type based on the data in Figure 7, and column 3 the information from borelogs. 
Table I. Classification of soil profiles.

\begin{tabular}{|c|c|}
\hline Profile & Type \\
\hline $\mathrm{A} 67 \mathrm{a}$ & 1 \\
\hline A67 & II \\
\hline $\mathrm{A} 73$ & I \\
\hline A75 & I \\
\hline B59 & II \\
\hline B61. 66 & I \\
\hline B42 & II \\
\hline B48 & II \\
\hline B52 & II \\
\hline $\mathrm{C} 38$ & II \\
\hline C34 - 35 & I \\
\hline $\mathrm{C} 33$ & I \\
\hline D23 & I \\
\hline D22 & I \\
\hline D11 & II \\
\hline $\mathrm{E} 2$ & I \\
\hline $\mathrm{E} 1$ & I \\
\hline E6 & I \\
\hline E5 & I \\
\hline E15 & II \\
\hline $\mathrm{E} 4$ & I \\
\hline E8 & I \\
\hline
\end{tabular}

Table II. Results of measurements with the E-phase unit at a frequency of $17.8 \mathrm{kHz}$ (NLK, Cutler, Maine).

\begin{tabular}{ccc} 
VLF & $\begin{array}{c}\text { Impedance phase angle } \\
\text { Profile }\end{array}$ & $\begin{array}{c}\text { between } E_{\mathrm{Z}} \text { and } E_{\mathrm{X}} \\
(\mathrm{deg})\end{array}$ \\
\hline
\end{tabular}

\begin{tabular}{lrl} 
A77 & 80 & 70 \\
A76 & 70 & 62 \\
A73 & 70 & 70 \\
A67 & 200 & -- \\
B62 & 40 & 58 \\
B59 & 20 & 52 \\
B42 & 55 & 45 \\
C35 & 30 & 52 \\
C30 & 40 & 60 \\
D22 & 25 & 60 \\
D13 & 40 & - \\
E15 & 80 & 66 \\
E2 & 120 & 66 \\
E4 & 100 & 60 \\
E9 & 100 & 58 \\
E5 & 240 & 58 \\
E8 & 110 & 54 \\
E6 & 140 & 55 \\
\hline
\end{tabular}

All the profiles in Figure 6 can be classified in two major types.

In type I a layer of fine-grained soil (CL, ML, MH, SC) overlies a second layer of coarsegrained soil (SM, GM, GP, SP), which is underlain by a layer of clayey soil (CL, CH, SC). In most instances the clayey third layer was in the Eutah formation. The first and second layers are of alluvial origin. The thickness of the fine-grained soil layer varies from 0 to $10 \mathrm{~m}$. In type II a fine-grained layer of alluvium directly overlies the Eutah formation which contains the clay. Coarse-grained soil is absent. The profiles are classified according to type in Table 1.

The results of the E-phase method using a frequency of $17.8 \mathrm{kHz}$ (VLF) from NLK, Cutler, Maine, are given in Table II. From Figure 5 it can be seen that the depth of penetration of VLF radiation is about $50 \mathrm{~m}$ at $200 \mathrm{ohm}-\mathrm{m}$, which is an average resistivity value for the top layer encountered in the area. The VLF unit, therefore, mainly reflects the resistivity of the Eutah formation. However, the VLF is also somewhat influenced by the thickness of gravel occurring above the Eutah formation. In Figure $9 \mathrm{a}$ and $\mathrm{b}$ the apparent resistivity at $20 \mathrm{kHz}$ is computed for three layer situations. A fine-grained topsoil of $200 \mathrm{ohm}-\mathrm{m}$ overlies sand and gravel of 500 or $1000 \mathrm{ohm}-\mathrm{m}$. The lower layer is the Eutah formation. When the thickness of the gravel increases, the apparent resistivity that one expects to measure also increases. Based on the computations shown in Figure 9a and $b$ an estimate of the amount of gravel in a profile can be made from the VLF measurements.

In Table III the soils are placed in three classes based on VLF data. The classification is compared with the classification from the boreholes. The interpretation obtained with the Wenner spread method is also given. The agreement is good, taking into account that the resistivity range in SM, GM, SP and GP is from 300 to $2500 \mathrm{ohm}-\mathrm{m}$. When the gravels are clean, as in the E-pool, the agreement is very good. 


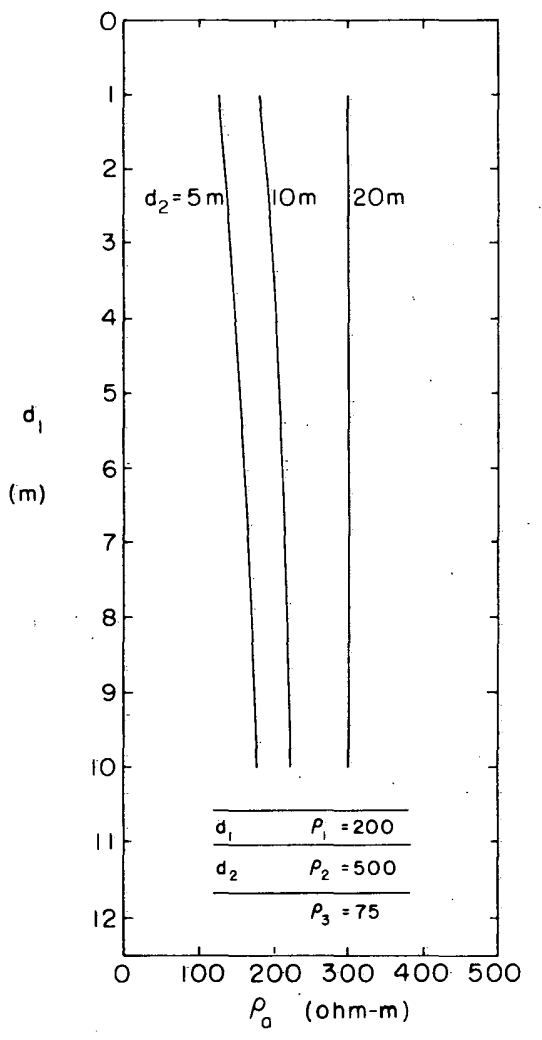

a. $20 \mathrm{kHz}$.

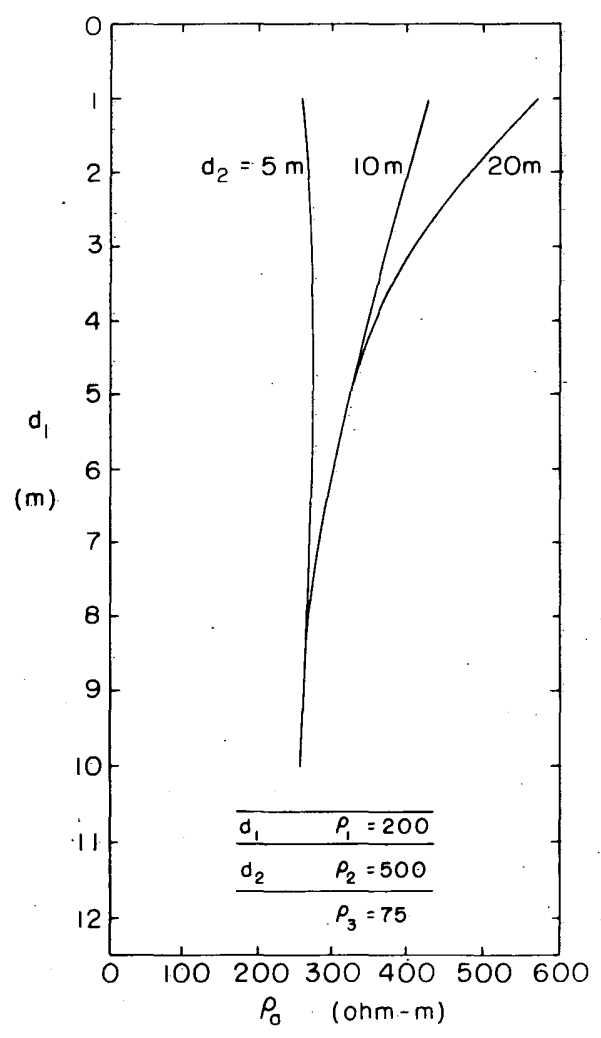

c. $200 \mathrm{kHz}$.

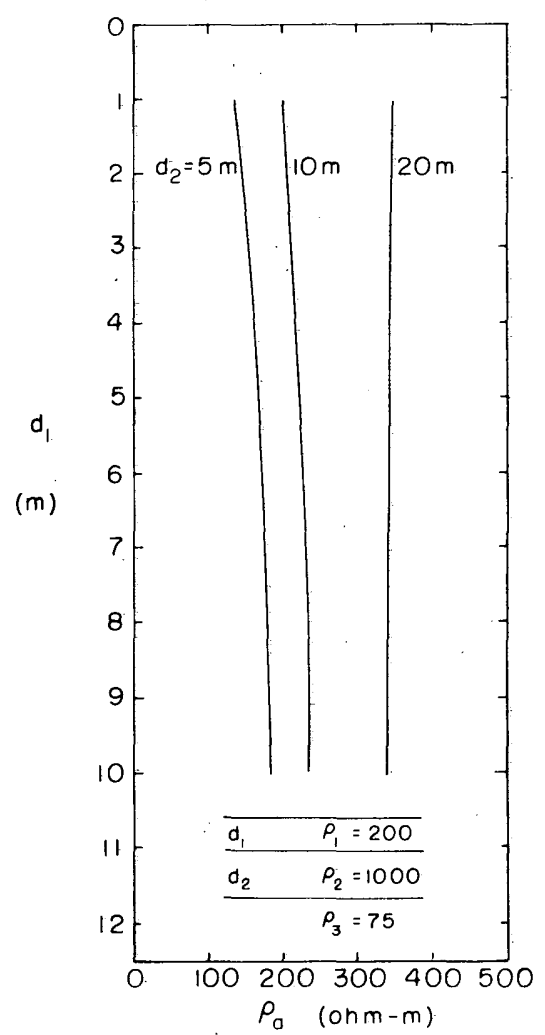

b. $20 \mathrm{kHz}$.

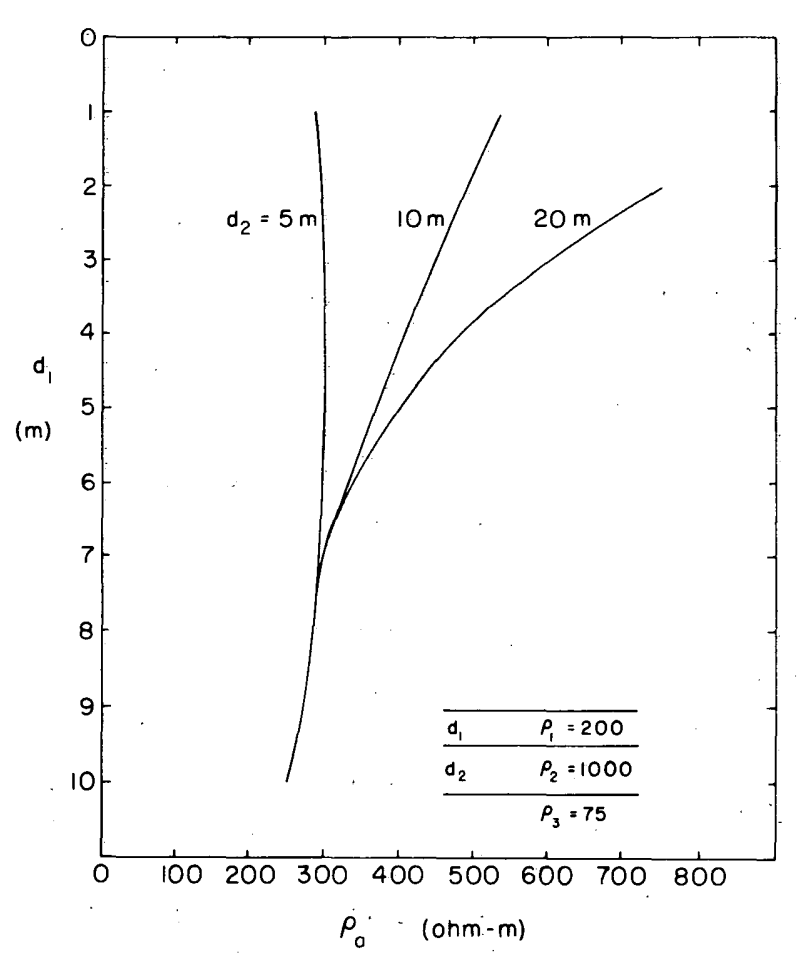

d. $200 \mathrm{kHz}$.

Figure 9. The computed apparent resistivity for the E-phase method for the layered situations shown on the figure. 


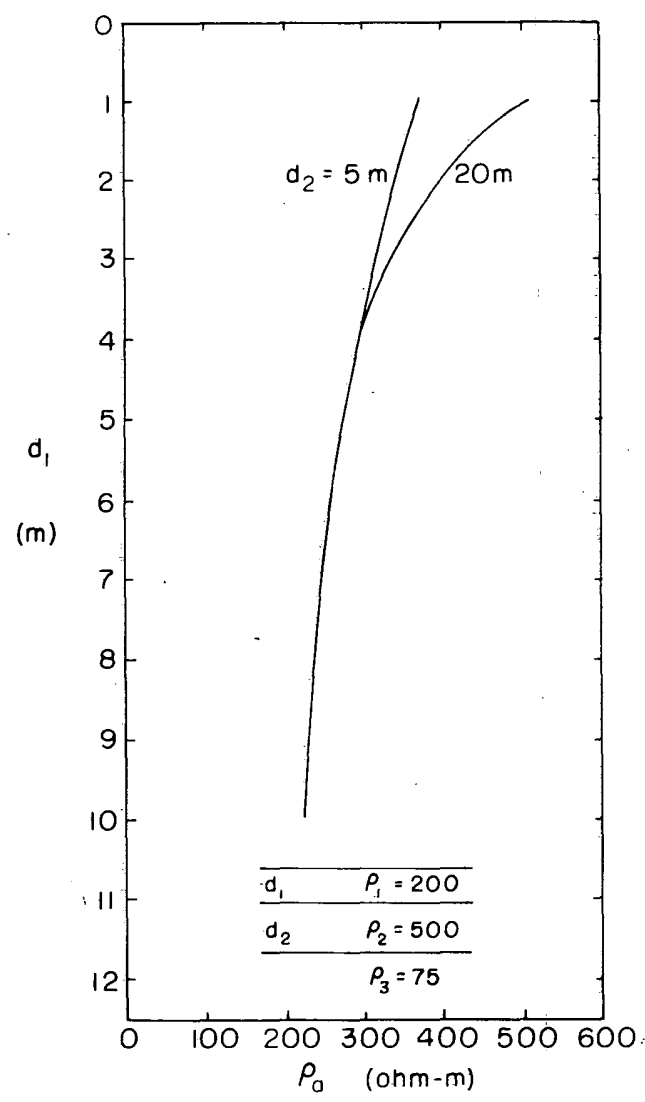

e. $600 \mathrm{kHz}$.

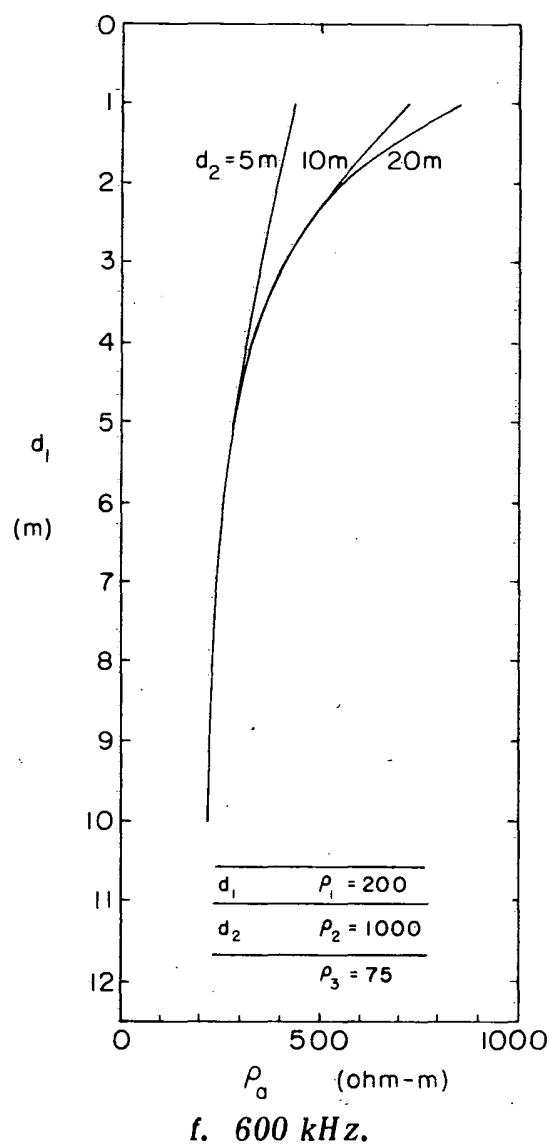

f. $600 \mathrm{kHz}$.

Figure 9 (cont'd). The computed apparent resistivity for the E-phase method for the layered situations shown on the figure.

\section{Modeling of the E-phase technique}

The airborne E-phase method can use frequencies from $20 \mathrm{kHz}$ to $1 \mathrm{MHz}$, and the question to be answered is: given the measured resistivity profiles, can the E-phase method serve the following project objectives?

1. In a typical profile (type I) in the area, fine-grained soil (CL, MH, ML, SC) overlies coarse-grained soil (SM, GP, GM, SP). One important objective of an airborne survey is to map the thickness of the fine-grained soil to an accuracy of $\pm 2 \mathrm{ft}$.

2. Deep, extensive gravel layers are a major consideration in the project. Another important objective is to detect continuous gravel layers between the surface and the Eutah formation.

What an airborne survey will show can be calculated. The numbers that are entered into the computer program are the values of the resistivity of typical profiles of type I and type II soils.

It is important in the modeling to recognize that a highly conductive stratum underlies all of the area. The origin of this conductive layer is the bentonitic clay in the Eutah formation. In Figure 10 the computed apparent resistivity is given as a function of frequency for type I soils. The resistivities and layer thicknesses used in the modeling are indicated in the figures. Clearly, at the higher frequencies the thickness of the fine-grained top layer causes substantial differences in apparent resistivity, while at VLF the top layer has little or no influence. These data are 
Table III. Classification of soils based on bore logs ( $\square$ ) compared with classification from VLF measurements $(17.8 \mathrm{kHz})$ and theoretical computations ( $)$ as given in Figures 7 a and $b$. The interpretation obtained with the Wenner spread method is also given(•).

$\left(\rho\right.$ is given in ohm-meters; $d_{\boldsymbol{g}}:=$ thickness of gravel.)

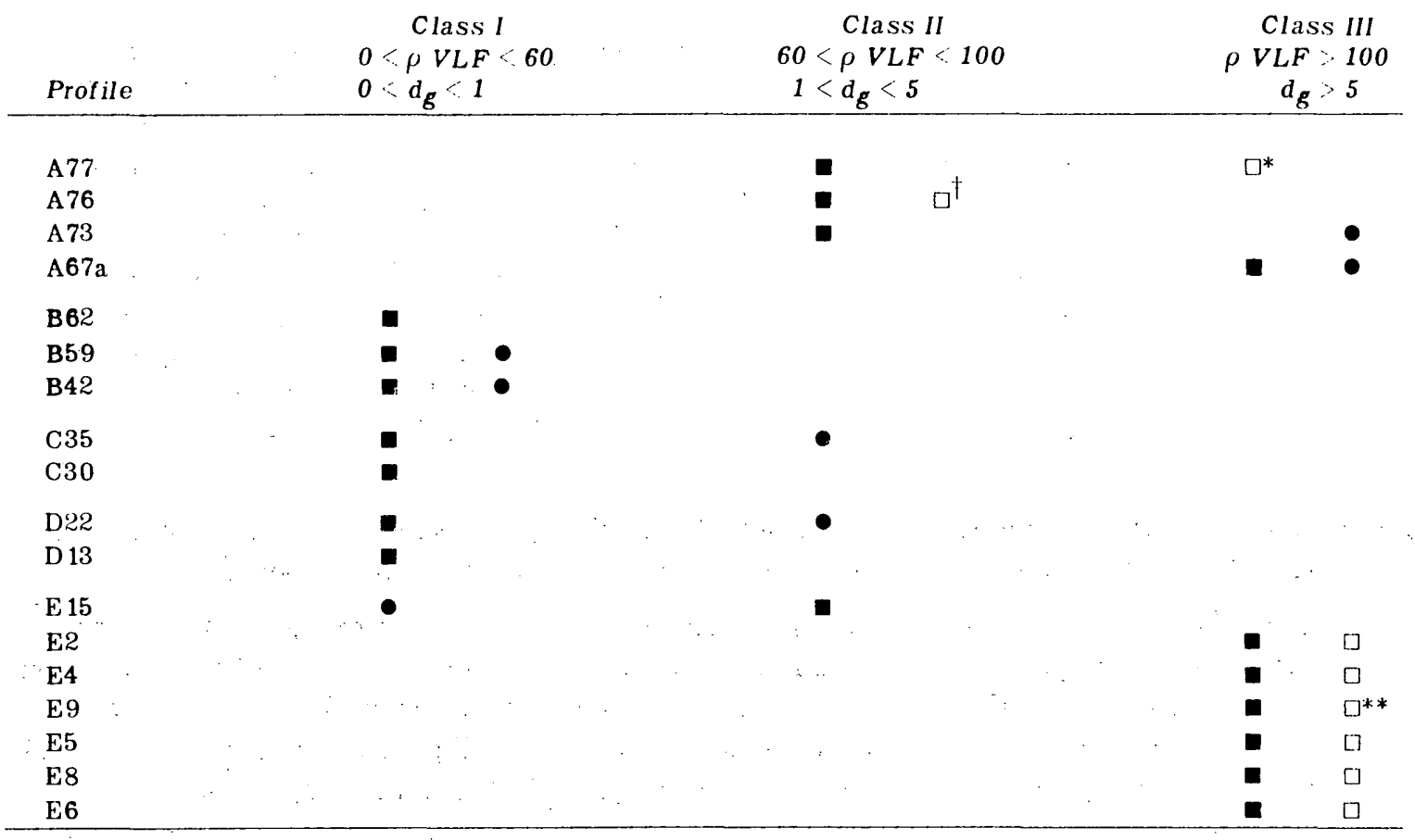

* Coarse-grained material is SM, 2.ft clay layer in SM.

$\dagger$ Top of Eutah at $21 \mathrm{ft}, \mathrm{SM}$ encountered in Eutah.

** Sandstone encountered in this profile.

considered in more detail in Figure 9 where the computed apparent resistivity is given as a function of the thickness of the top layer at different thicknesses of the underlying sand and gravel layer. The trends in the graph can be summarized as follows:

1. At VLF $(20-50 \mathrm{kHz})$ the radiation penetrates the top layer and the gravel layer, so that the apparent resistivity is mainly determined by the bentonitic clay in the Eutah formation. The thickness of the gravel layer influences the apparent resistivity by about a factor of three.

2. At frequencies of about $200 \mathrm{kHz}$ the apparent resistivity reflects the thickness of the gravel layer, if the thickness of the top layer is less than about $5 \mathrm{~m}$ (Figures $9 \mathrm{c}$ and d). If the thickness of the fine-grained top layer is more than $5 \mathrm{~m}$, the apparent resistivity is determined mainly by this layer.

3. At $600 \mathrm{kHz}$ the resistivity is determined mainly by the resistivity and thickness of the fine-grained top layer.

Type II soils are modeled in Figure 11. When the thickness of the $200 \mathrm{ohm}-\mathrm{m}$ top layer increases, the apparent resistivity reaches a constant resistivity.

On the basis of modeling, and assuming that a survey is flown at frequencies of about 20 . 200 and $600 \mathrm{kHz}$, one can set up the minimum classification that is possible from the airborne data (Table IV). In this classification the minimum contrast found between the top layer (200 ohm-m) and the sand and gravel layer ( $500 \mathrm{ohm}-\mathrm{m})$ has been used. In many instances lower resistivities were found for the top layer, and larger resistivities for the gravel. The value of the VLF 
Table IV. Minimum classification possible from

2- or 3-frequency airborne survey.

\begin{tabular}{|c|c|c|c|c|}
\hline \multirow[b]{2}{*}{ Class } & \multicolumn{3}{|c|}{ Frequency $(\mathrm{kHz})$} & \multirow[b]{2}{*}{ Interpretation } \\
\hline & 20 & 200 & 600 & \\
\hline $\mathrm{I}$ & $<100 \mathrm{ohm} \cdot \mathrm{m}$ & $<250$ ohm-m & $<.250 \mathrm{ohm} \cdot \mathrm{m}$ & $\begin{array}{l}\text { Less than } 5 \mathrm{~m} \text { of sand and gravel. } \\
\text { Fine-grained soil extends to Eutah } \\
\text { formation. }\end{array}$ \\
\hline U & $100 \cdot 150 \mathrm{ohm}-\mathrm{m}$ & $250 \cdot 350 \mathrm{ohm} \cdot \mathrm{m}$ & $250 \cdot 400 \mathrm{ohm}-\mathrm{m}$ & $\begin{array}{l}\text { Fine-grained top layer more than } \\
1 \mathrm{~m} \text { and less than } 5 \mathrm{~m} \text { thick. More } \\
\text { than } 5 \mathrm{~m} \text { of sand and gravel in } \\
\text { prof ile above Eutah formation. }\end{array}$ \\
\hline III & $>150 \mathrm{ohm}-\mathrm{m}$ & $>350 \mathrm{ohm}-\mathrm{m}$ & $>400 \mathrm{ohm}-\mathrm{m}$ & $\begin{array}{l}\text { Fined-grained top layer less than } \\
1 \mathrm{~m} \text { thick. More than } 10 \mathrm{~m} \text { of sand } \\
\text { and gravel in prof ile. }\end{array}$ \\
\hline
\end{tabular}

data is minimal; the same classification can probably also be derived from a survey at 200 and $600 \mathrm{kHz}$. The VLF data would mainly be used to identify extensive clean gravels.

In general, the function of the $600-\mathrm{kHz}$ frequency is to identify the top layer, and the function of the $200 \mathrm{kHz}$ frequency is to classify the thickness of gravel between the Eutah formation and the top layer. For example, if in a profile the top layer of fine-grained soil had a thickness of $5 \mathrm{~m}$, the apparent resistivity at $600 \mathrm{kHz}$ would be $280 \mathrm{ohm}-\mathrm{m}$ (Fig. $9 \mathrm{f}$ ), regardless of the thickness of the underlying gravel or the resistivity of the ground. The resistivity of the top layer has, of course, a major influence. The apparent resistivity at $200 \mathrm{kHz}$ would show in this situation (Fig. 9c) a resistivity of 260,375 or $400-\mathrm{ohm}-\mathrm{m}$ depending on the thickness and resistivity of sand and gravel.

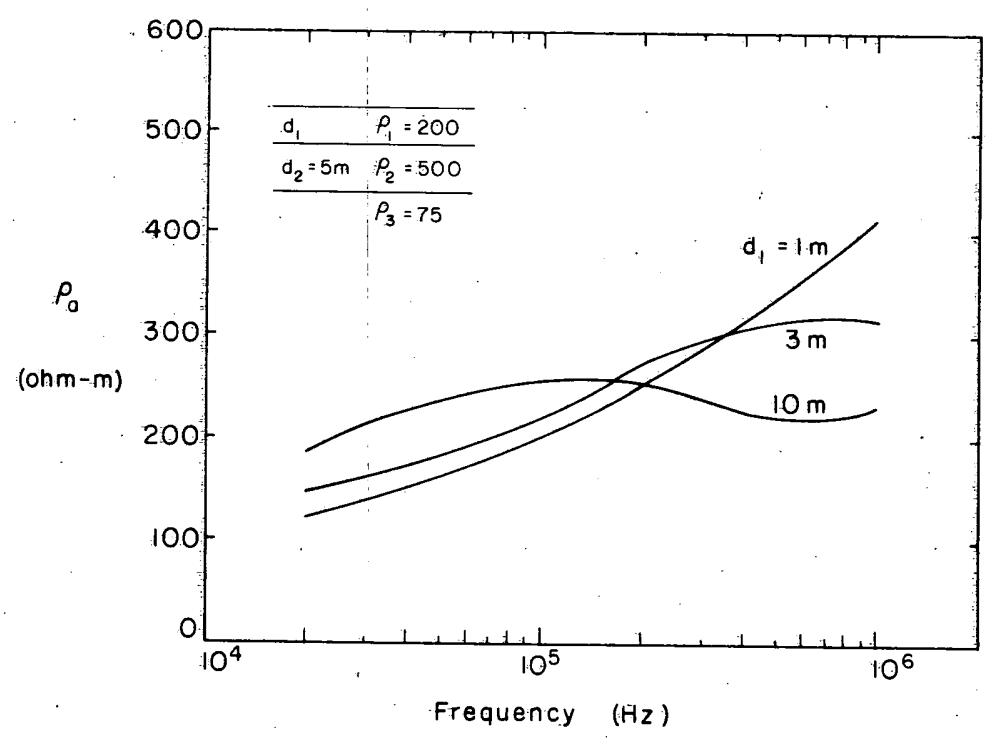

a.

Figure 10. The apparent resistivity computed for the E-phase method for the layered situations shown on the figure. 


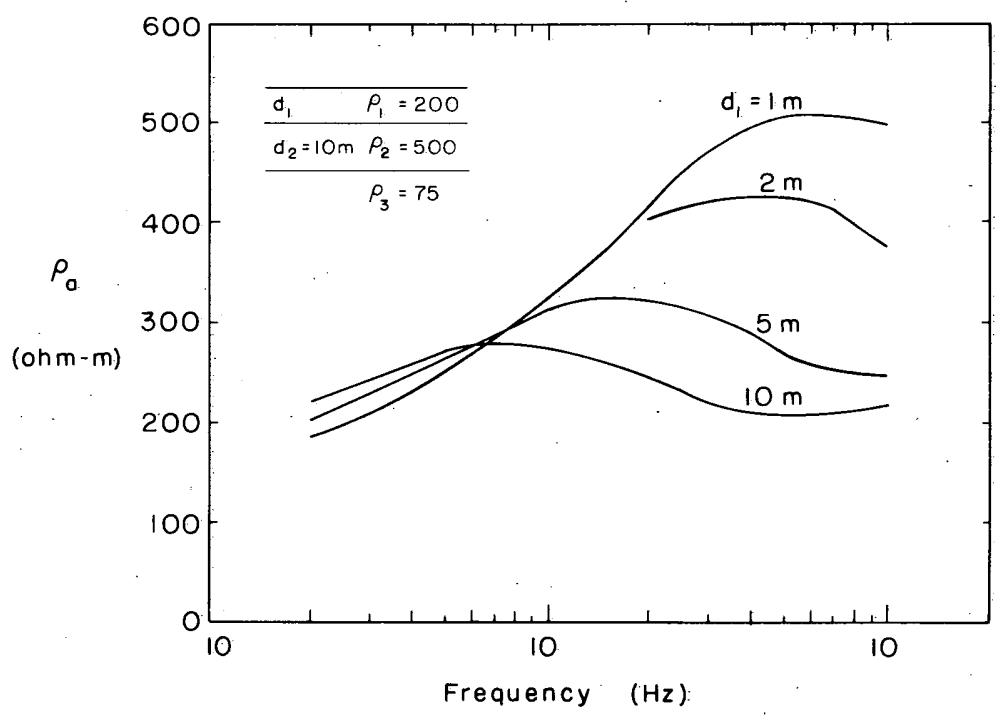

b.

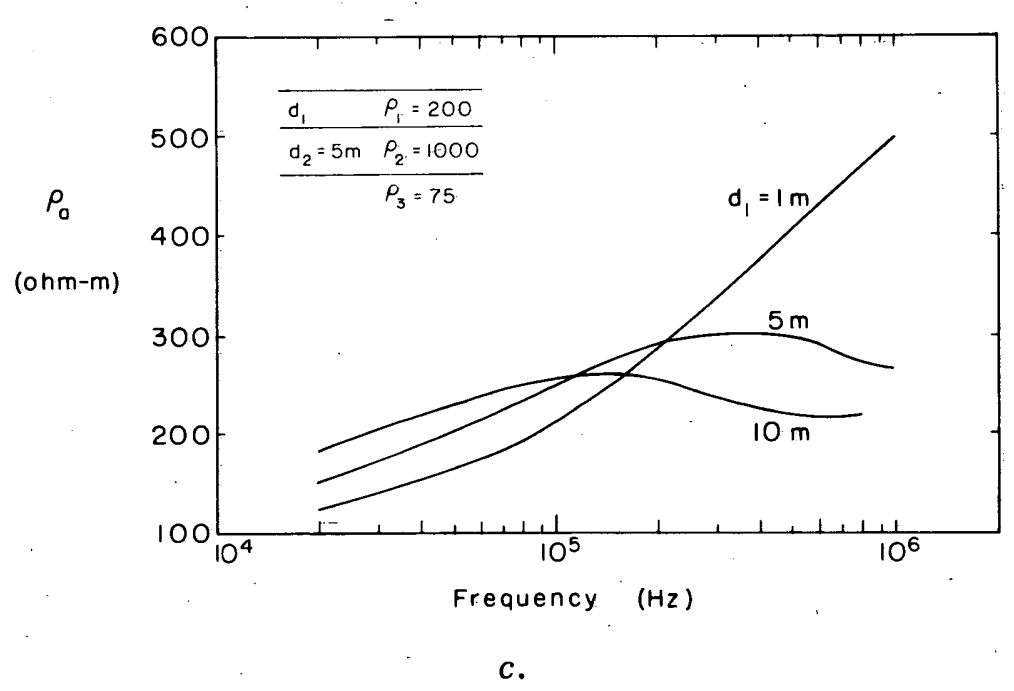

Figure 10 (cont'd). The apparent resistivity computed for the $E$-phase method for the layered situations shown on the figure. 


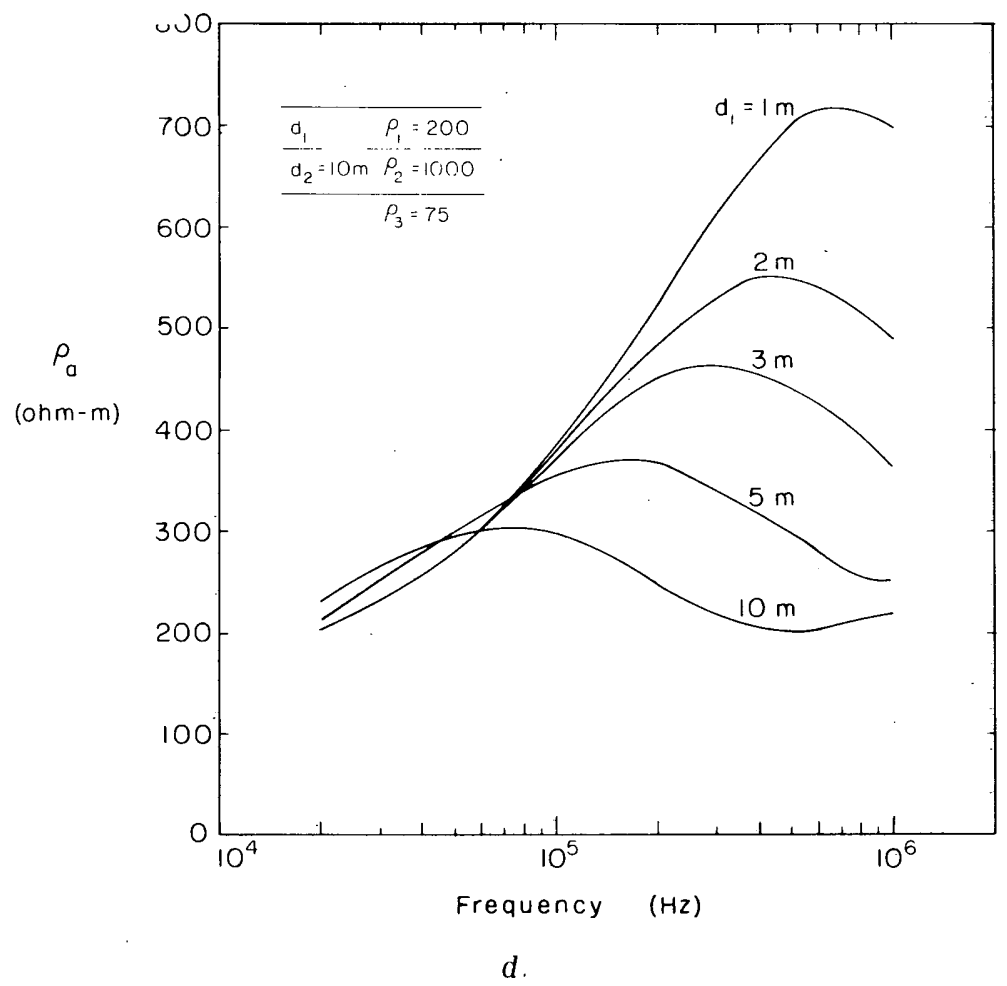

Figure 10 (cont'd). The apparent resistivity computed for the $E$ phase method for the layered situations shown on the figure.

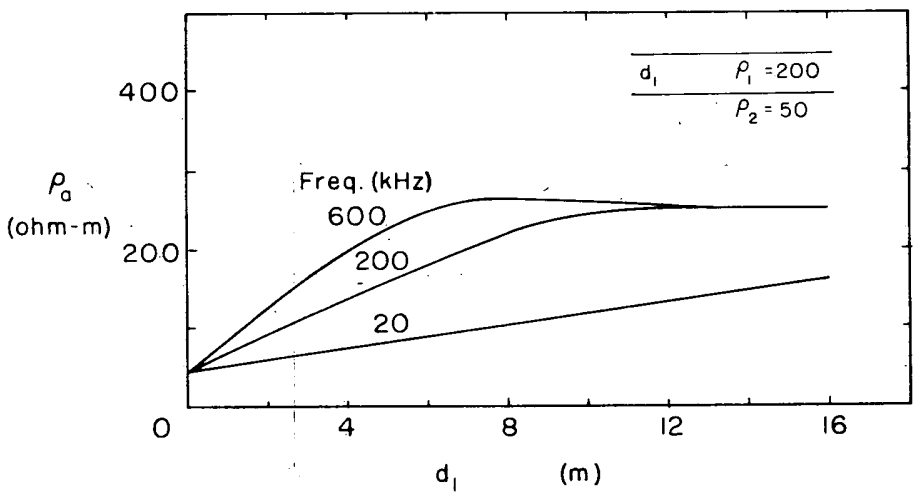

Figure 11. The apparent resistivity computed for the E-phase method for the layered situation shown on the figure. 


\section{Conclusions and recommendations}

The classification possible from a two- or three-frequency airborne survey (Table IV) falls far short of the objectives stated by the Mobile District.

The thickness of the fine-grained top layer can probably only be mapped within classes of less than $1 \mathrm{~m}, 1$ to $5 \mathrm{~m}$, and more than $5 \mathrm{~m}$. The initial objective stated was an accuracy of $\pm 2 \mathrm{ft}$. The sand and gravel layer under the top layer and above the Eutah formation can probably be mapped within classes of $0-5 \mathrm{~m}, 5-10 \mathrm{~m}, 10-20 \mathrm{~m}$ and more than $20 \mathrm{~m}$. Based on these findings the following recommendations are made:

An airborne resistivity survey should be flown only if:

1. The local variation between adjacent boreholes, both along the canal route and perpendicular to the canal, is of the same magnitude as the upper and lower limits of the soil classes stated in Table IV. For example if the variation in the thickness of the fine-grained top layer between adjacent boreholes is $9 \mathrm{ft}$ or more, an airborne survey will yield more consistent information because of its continuous coverage.

2. There are large areas where access is extremely difficult and costly. In these areas even a classification as listed in Table IV would be valuable.

\section{Literature cited}

Hoekstra, P. and D. Mc Neill (1973) Electromagnetic probing of permafrost. Second International Conference on Permafrost, Yakutsk, U.S.S.R.

Keller, G.V. and F.C. Frischknecht (1966) Electrical methods in geophysical prospecting. New York: Pergamon Press. 


\section{DOCUMENT CONTROL DATA - R \& D}

Security classification of title, body of abutract and indexing annotation must be ontered when the overall reporf. $1 \mathrm{~s}$ claseilled.).

OFIGINATING ACTIVITY (Comporate aUthor) ZE.REPORT SECURITY CLASSIFICATION

U.S. Army Cold Regions Research and

Engineering Laboratory Unclassified

Hanover, New Hampshire 03755

2b. GROUP

T. REPOAT. TIT-LE

GROUND RESISTIVITY SURVEY IN AREA OF TENNESSEE - TOMBIGBEE WATERWAY

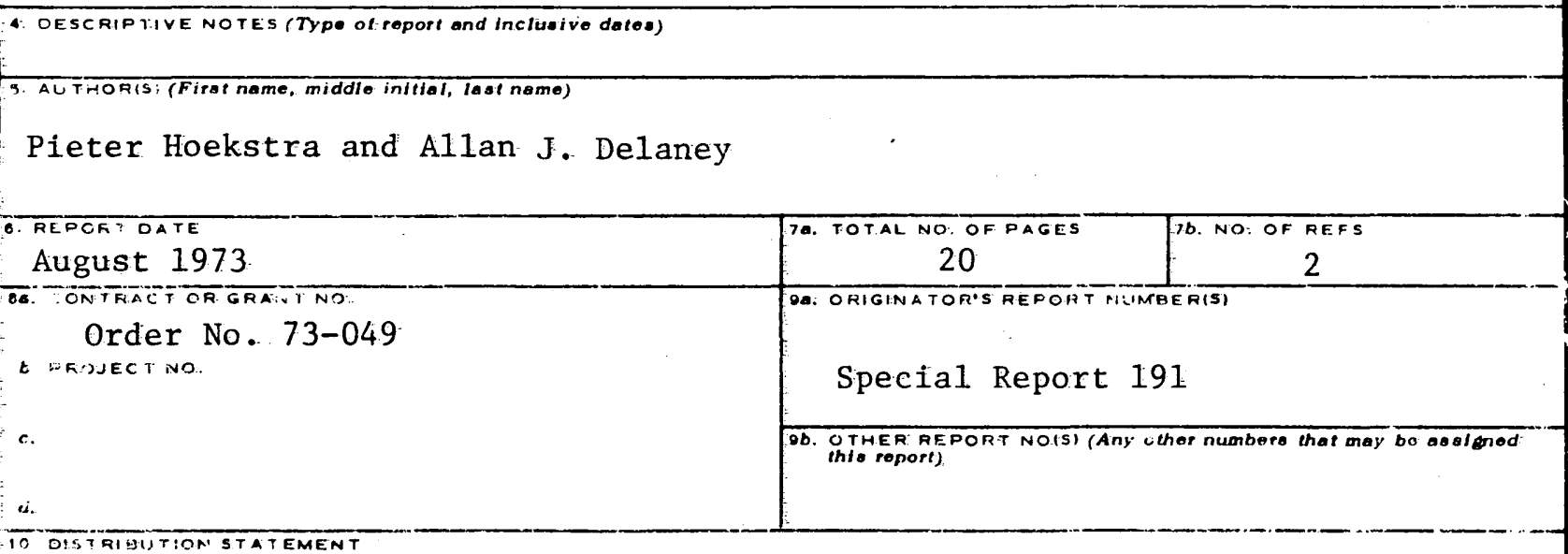

Approved for public release; distribution unlimited.

\begin{tabular}{|c|c|}
\hline 11. SUPPLEMENIARY NOTES & $\begin{array}{l}\text { Office of the District Engineer } \\
\text { U.S. Army Engineer District } \\
\text { Mobile, Alabama }\end{array}$ \\
\hline
\end{tabular}

Electrical resistivity measurements were made on the ground in the area of the proposed Tennessee Tombigbee Waterway in the vicinity of Fulton, Mississippi. The objective of the project was to determine if electrical resistivity surveys could be used to advantage in exploration required for the canal section. In general in this area a layer of fine-grained material overlies sands and gravels. In most of the area a bentonitic layer is situated at a depth from 10 to $90 \mathrm{ft}$ below the surface. The conclusion was reached that an airborne resistivity survey would probably map the fine-grained top layer within classes of $0-1 \mathrm{~m}, 1-5 \mathrm{~m}$, and more than $5 \mathrm{~m}$ thick. Clean, extensive gravel layers. would also be detected.

\section{KEY WORDS}

Aerial surveys

Electrical resistivity

Geological surveys

Soil surveys

Subsurface investigations 